\title{
Visual analytics for railway network in Java Island
}

Febrian Fitryanik Susanta

Febrian Fitryanik Susanta, "Visual analytics for railway network in Java Island," Proc. SPIE 11311, Sixth Geoinformation Science Symposium, 1131108 (21 November 2019); doi: 10.1117/12.2548481

EDIE Event: Sixth Geoinformation Science Symposium, 2019, Yogyakarta, Indonesia 


\title{
VISUAL ANALYTICS FOR RAILWAY NETWORK IN JAVA ISLAND
}

\author{
Febrian Fitryanik Susanta ${ }^{a}$ \\ ${ }^{a}$ Department of Geodetic Engineering, Faculty of Engineering, Universitas Gadjah Mada, Indonesia \\ 55281, febrian.fitryanik.s@ugm.ac.id
}

\begin{abstract}
Train is one of mass transportation that contains spatial and attribute data. Based on one of the development services of the 2030 national railway, the innovation of Indonesian Ministry of Transportation is focused on the ease of uses, namely the public, academics, and policy-makers to access data and information through web-based maps (WebGIS). At present, railways data in Indonesia have been publicly accessible. But general visualization of railways data, which is clear and easily understood by the public have not available. Therefore, this research aims to visualize the results of railways data which interactively combining spatial data and attribute data. The data used for this research was obtained from the Indonesian Ministry of Transportation. Visualization of the data requires a search for patterns, relationships and trends. The data variables used in this research include railways status, station status, station class, station group, the distance between stations, as well as the location of stations and railway lines. The results of the data processing are maps presented in a dashboard map view with visual analytics features. The data are processed with QGIS then are visualized by Operations Dashboard for ArcGIS. Visual analytics method is used because the results can show the relationship between variables. It can be used as a reference for decision making to develop transportation infrastructure, especially of rail transportation. Maps and graphics are visually interactive so change one attribute can affect the other attribute display. The result of this research is named Railway Network in Java.
\end{abstract}

Keywords: transportation, railway network, trains, web-map, visual analytics

\section{INTRODUCTION}

Mass transportation has an important role to improve economic conditions in supporting population mobility, goods, and services. Trains are one of the most effective mass transportations with efficient travel time and large capacity. In accordance with the national railway development in 2030, one of the strategies is the development of railway networks and services [1]. Network development planning needs considering several factors, such as the condition of the railroad network and railway station. Both of factors need to be visualized to facilitate analysis and observation so support spatial decision making. It can be accommodated by building a web application such as a dashboard that can display maps and graphics at once. The dashboard is a web application can display dynamic and interactive visualization of spatial and non-spatial data. The dashboard views can be divided into web-map and graphical displays. Web-Map is a map connected to an internet network that is used to collect, store and display the georeferenced location of objects without the need for the use of GIS software [2]. Information on the railroad network contains location data and their attribute data. From these data, it brings out a challenge on how to present railroad network information with the best view so can get new insights that support decision making. Therefore, this research focuses on displaying of railway network data with dashboards view with research locations in Java Island.

The aim of this research is to display railroad network data and information on Java Island. The variables shown in this research are status, class, and group of a railway station as well as the distance and status of the railway network. Visualization of this variable use a dashboard display consisting of two views, namely map view and graphical view. A dynamic and interactive visualization use the visual analytical method, so users gain insight for decision making. Therefore, this research is expected to provide benefits for users, namely policymakers to monitor the railroad network in supporting decision making for the development of railway networks and services in Indonesia. On another, it's from the academics' side can bring up new research ideas on data visualization, visual analytics, web-map, or about railroad transportation. 


\section{RELATED WORK}

Railway network web-based map is equipped with visual analytics. Visual analytics aims to combine data processing from humans and computing. Good cooperation can use to analyze data and find patterns and trends so gain new insights [3]. Visual analytics combine analytical techniques automatically through interactive visualization for effective understanding, reasoning, and decision making at the basic level [4]. Andrienko et al (2007) said that the use of appropriate visual analytics can help analyze the data set [5]. Visual analytics effectively supports the understanding, awareness, and users' needs with database operations and computational methods so can visualize large amounts of data. Ramos et al (2015) in their research used visual analytics to combine data analysis techniques and interactive visualization to obtain information from extensive and complex data [6]. Visual analytics accommodates the exploration of spatial based temporal data through maps consisting of various variables and parameters for analysis. Through this method, it's can gain new understanding which then improves and supports the decision-making process. Whereas, in other studies [7], conducts literature reviews to explain several alternative methods in the selection of transportation modes. Visual analytics is a science of visualization seeks to display analytical thinking and interactive visual display. The use of visual analytics in relation to the visualization of network modeling has been done by Lu et al (2018) [8]. Visual analytics as a framework to display complex dynamic data on world trade networks. This framework is also used to analyze the relationship between the trade network and regional instability. Visual analytics method is also used in traffic networks [9]. It's explained how the system produces a network pattern model of knowledge representation and display the results interactively.

In this research, visual analytical methods were displayed through the dashboard view. The railway network dashboard consists of the map view and graphic views as widgets. The visualization uses visual analytical methods to combine spatial information and attribute information with interactive visualization to gain new insights from railroad network data on Java Island so support railroad network development and arrangement.

\section{METHODS}

\subsection{Data Sets}

The used data in this paper are based on the entire railway network on Java Island. It obtained in 2017 from Directorate General of Railways at the Indonesian Ministry of Transportation. The data are coordinate values with attribute data of railway lines and railway station. Railway lines consist of active and inactive line. The railway station also covers an active and inactive station. In addition, there are nine operating areas of trains in Java Island.

\subsection{Data Processing}

The data processing includes spatial and non-spatial data processing. Data processing has been done using QGIS software. The spatial features in the map view are point features represent the location of the station and the line features represent the railroad tracks connect between stations. While completed attribute information for non-spatial data. After ensuring attribute data is complete and ready to use, then combine the attribute data to spatial data that has reference coordinates. The topologies formation and development have been carried out according to topological rules for line and point features. Furthermore, correct to the error features and save the data in the shapefile format for upload to the web.

\subsection{Designing Web-Map}

Designing web-map have been done using ArcGIS Online. The results of data processing have uploaded as feature layers (hosted). Designing web-map have started on determining the mapped area and selecting a base map from Open Street Map. Then add previously processed data and map customization. Map customization includes choosing the right visual variables to spatial data and their attributes. The station features using train station symbols with different colors, blue for active stations and red for inactive stations. Meanwhile, the railroad network features using a dotted line rail in black and white for active lines as well as black and red for inactive lines. Next, the pop-up configuration, to display attributes information when the user selects a feature on the map. The final step is to settings a bookmark. Bookmark settings to make users easier select the location of the desired map display. The selected bookmarks are nine operating areas in Java Island.

\subsection{Designing Dashboard}

Designing dashboard has been done using the Operations Dashboard for ArcGIS web application. Operations Dashboard is a configurable web application to display a Web Map and visualize the results of data analysis in the form of a 
graphical view. The dynamic and interactive dashboard can be used to gain new insight from the data displayed and support decision making. Designing the dashboard starts with configuring map tools to set the map functions and selecting display themes. The selection of themes and colors crucial to support information visualization and set the focus of the user. Besides color selection, symbolization also supports functions on the map. The symbolization of cartography is essentially the selection of appropriate and creative symbols can describe spatial and attribute data, Bertin (1983) calls "visual variables" in DiBiase et al. [10]. There are seven different visual variables for each geometry type to describe spatial information and attributes of maps, namely position, size, value, texture, color, direction, and shape.

Element configuration to set attribute information views interactively and dynamically functions on the dashboard. These elements are also known as widgets. The dashboard configuration includes header settings, category selector settings for easier the user to find locations on maps and set the other widgets. The widget of the bar graph to visualize the number of the railway station, the number of slags between railway stations, as well as the status of the railway station and railway network. Whereas to visualize railway station class and group using a circle graph display and percentage number of them. For the average distance be displayed using a number indicator. Each graph view and map view are interconnected so when the user gives a query on one view, the other views automatically change.

\section{RESULTS AND DISCUSSION}

The result of this research was a dashboard displays the railway network and railway stations in the form of map view and graph views, which are named the Railway Network in Java. The dashboard visualization using visual analytical methods with target users, namely policymakers to find patterns and trends so gain new insight for decision making. Users can monitor the condition of the railroad network dynamically and interactively using dashboard visualization. Users immediately know the location and graphical display from giving a query for each attribute information. These functions facilitate users to arrange and develop a railroad network so improve service to the community. Visual analytics combines the power of processing data from humans and computing where both works together to achieve understanding by users. The dashboard results of this research as presented in Figure 1.

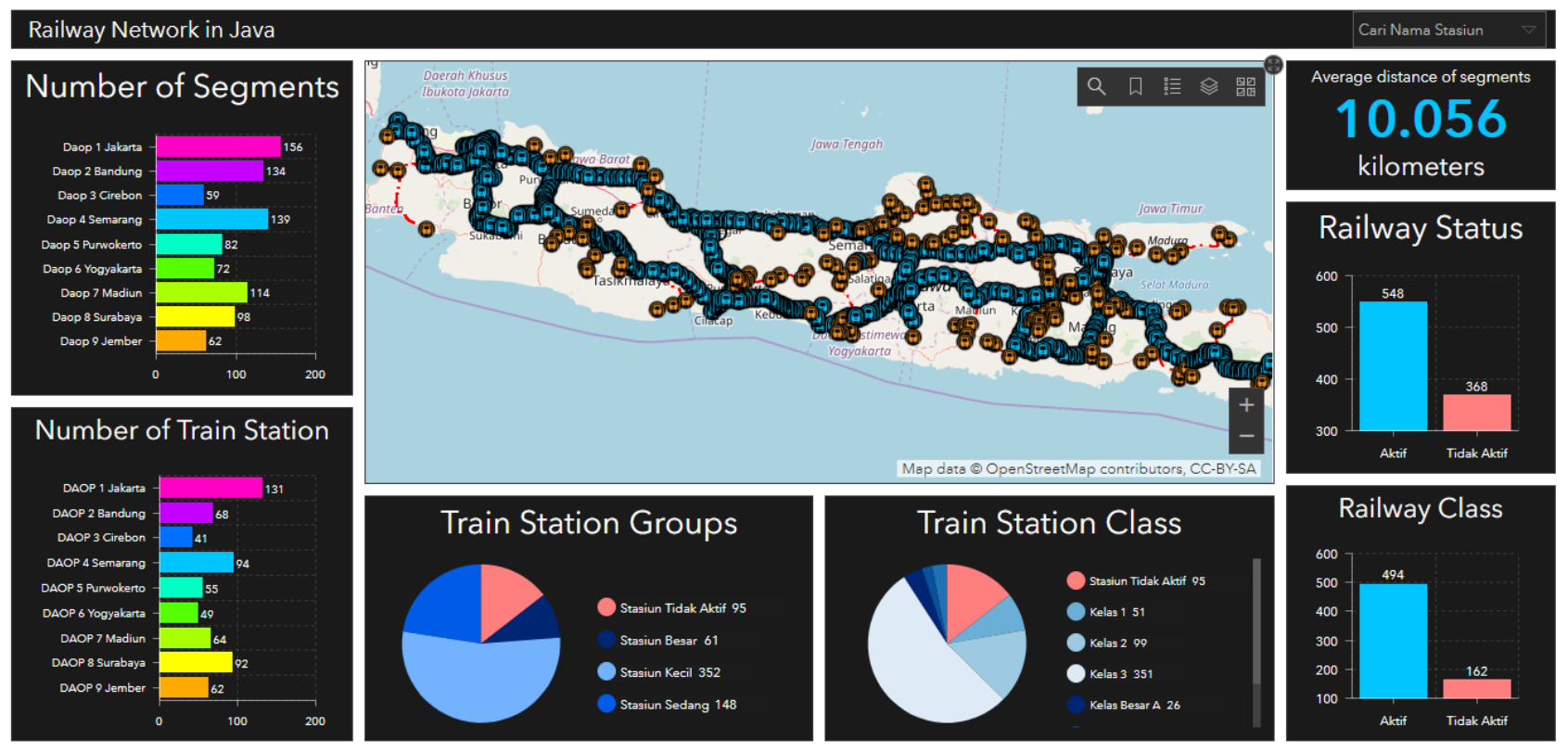

Figure 1. The dashboard view of "Peta Jalur Kereta Api Jawa"

This dashboard uses of dark themes, so users focus on the information visualized. While the color selection for the data presentation uses consistent and uniform colors. This shows that all data still related. In this research, the visual variables used to describe the diversity data are indicated by differences in color and shape for quantitative data and differences in values for qualitative data. While the main components in this map are the location of railway stations and railway network in Java Island. The map is equipped with pop-ups, scale bars, default extent and bookmarks, legend, layer visibility, base map switcher, search, pan and zoom in / out. The web-map view is shown in Figure 2. When selecting a 
feature, the pop-ups function is displayed. For railway station features, the attributes displayed include the operation area station, station class, station group, and station status. As for the railway network features, the attributes displayed include the start of the $\mathrm{km}$, the end of the $\mathrm{km}$, the distance from the initial station to the end station, operation area, and the status of the railway network. In addition, users can choose to focus on one operation area so easy to do an analysis of each operation area.

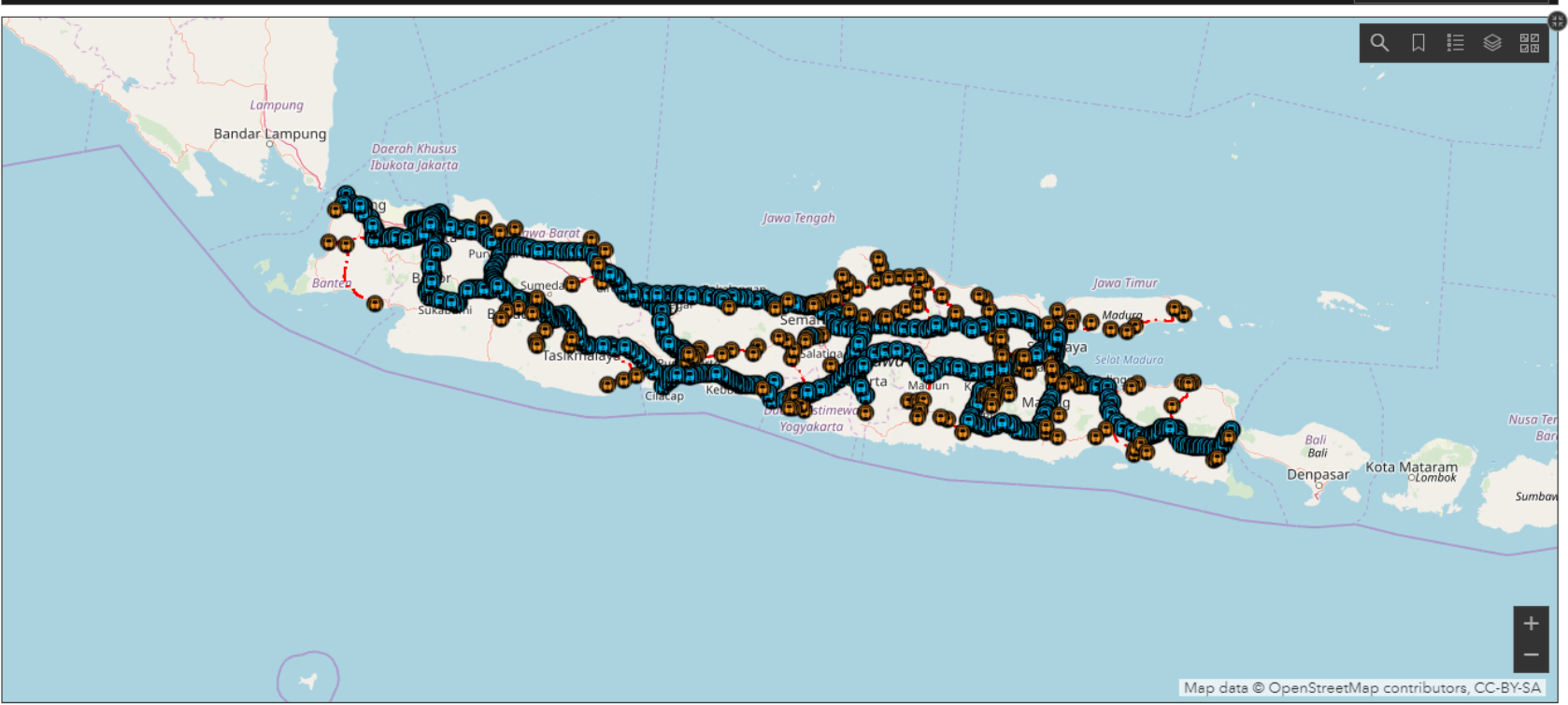

Figure 2. The map view of "Peta Jalur Kereta Api Jawa"

In this research, there were seven elements of widgets added. Two bar graph vertical displays the number of stations and the number of slags between stations with different color choices for each operating area. Two bar graph horizontal displays the number of railway network status and railway station status with the same color selection as in the map legend. Two circle graph displays the number of railway station group and station class with visual variables in the form of values. In this research, geovisualization is presented with a visual analytic method that allows users to think visually. Users can explore and confirm the map presented. Users are required to understand the pattern of relationships in the data displayed so user interactions with dashboard are very high. Thus, users can obtain information stored in the dashboard. The use of this method can support the analysis of spatial data visually interactively. This method can support gain the knowledge and new insights from the data presented to bring new understanding as well as supporting decision making.

\subsection{Example of Analysis Queries}

Here we describe several queries that can be performed by users through the dashboard. There are three example queries involving the visual analytical method of railway network data. The users interactively can operate the tool in the dashboard to solve the queries and visually the results will be presented.

1. The user is chief of operating areas of the railway network in Jakarta. The user wants to find out the coverage of the railway network and railway station, including active and inactive, in the form of a map. Besides that, users want to monitor the conditions of the railways in the area in the numeric form. Therefore, the users can select "Daop 1 Jakarta" form two tools, Number of Segments and Number of Train Stations. At the bookmark of the map, the users also can choose a text of "Daop 1 Jakarta" to zoom the operation area which is chosen. The results from interaction users with the tools of the dashboard shown in Figure 3. 

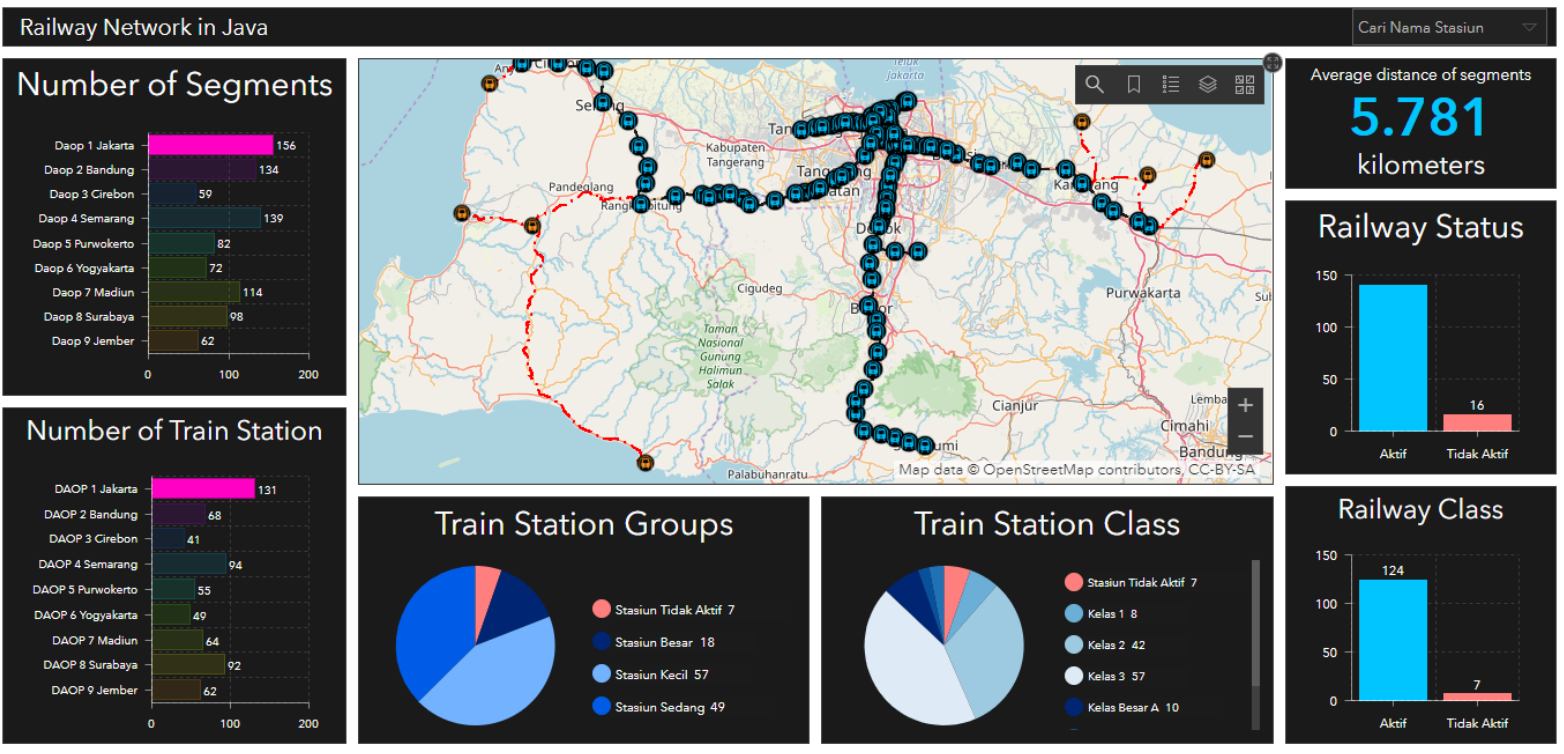

Figure 3. Examples of display requests by users (1)

2. The user only wants to find out the coverage of the active railway network and active railway station in the form of a map. Besides that, users want to monitor the conditions of the active railways in the numeric form. Therefore, the users can select "Aktif" form two tools, Railway Status and Railway Class. At the bookmark of the map, the users also can choose a text of "Jawa" to zoom the operation area which is chosen. The results from interaction users with the tools of the dashboard shown in Figure 4.

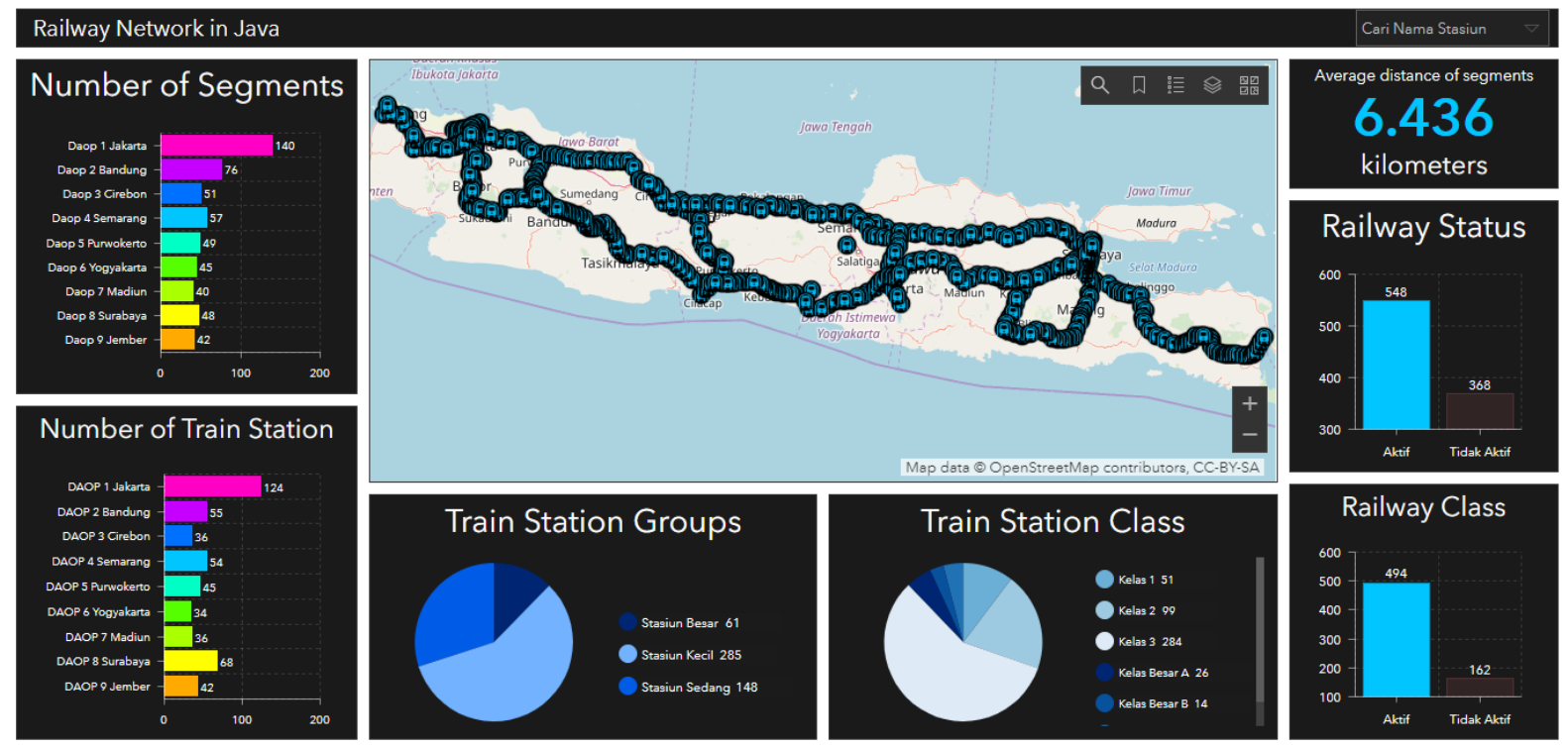

Figure 4. Examples of display requests by users (2)

3. The user is chief of operating areas of the railway network in Yogyakarta. The user only wants to find out the coverage of the inactive railway network and active railway station in only one operating area in the form of a map. Besides that, users want to monitor the conditions of the active railways in the numeric form. Therefore, the users can select "Tidak Aktif" form two tools, Railway Status and Railway Class. Then, the users also select "Daop 6 Yogyakarta" form two tools, Number of Segments and Number of Train Stations. At the bookmark of the map, the 
users also can choose a text of "Daop 6 Yogyakarta" to zoom the operation area which is chosen. The results from interaction users with the tools of the dashboard shown in Figure 5.

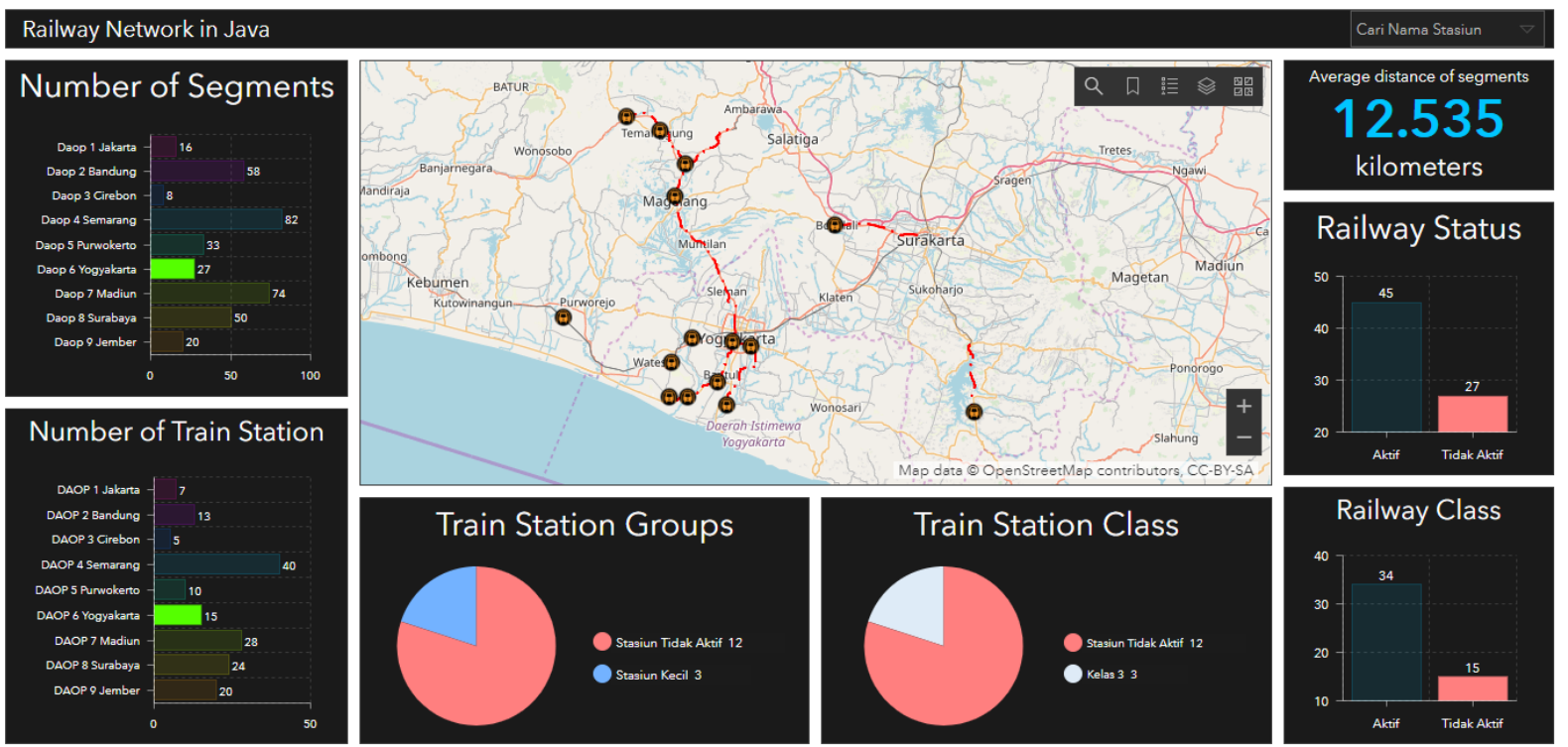

Figure 5. Examples of display requests by users (3)

\subsection{Analysis of the Results}

The aims of this research have been to develop the tools for visualization study of the railway networks in Java Island. A following goal was to find and to investigate the pattern and trends of the data in which visual analytics can support by combinations of visual interactive and computational techniques of the user. Consideration of several example queries of problem solving helped us to distill the key concepts. Users can get the insight differently depending on the interaction between users and tools of the dashboard. However, the result of this research only is a general framework for using visual analytics methods and workflows in railway network visualization.

\section{CONCLUSION}

Based on the research that has been done, this research has produced the dashboard of the railway network on Java Island. The dashboard consists of a map view and graphical view that dynamically and interactively to support visual analytical functions. The results are named the Javanese Railway Map. The map view visualizes the location of stations and railway lines on Java Island, equipped with pop-ups, scale bars, default extent and bookmarks, legend, layer visibility, base map switcher, search, pan and zoom in / out. Meanwhile, the graphical view visualizes the view of the number of stations and slags between stations in each operation area, station class, station group, station status, and the average railroad distance. The graph used consists of bar graphs and circle graphs. These two views are interconnected so when having given a query on one view, it automatically has changed the appearance of the others. This dashboard makes policymakers easy to monitor railroad conditions so support railroad network development and arrangement to improve service to the community, especially in the field of rail transportation.

\section{ACKNOWLEDGMENTS}

The author would like to thank Directorate General of Railways at the Indonesian Ministry of Transportation have been providing data for this research. 


\section{REFERENCES}

[1] Kementerian Perhubungan RI, Rencana Induk Perkeretaapian Nasional. Pemerintah RI, Jakarta, (2011)

[2] Painho, M., Peixoto, M., Cabral, P., Sena, R., "WebGIS as a Teaching Tool," Proceedings of the ESRI UC, 913 (2001).

[3] Andrienko, G., Andrienko, N., Demsar, U., Dransch, D., Dykes, J., Fabrikant, S.I., Jern, M., Kraak, M.-J., Schumann, H., Tominski, C., "Space, Time and Visual Analytics," International Journal of Geographical Information Science 24, 1577-1600 (2010).

[4] Keim, D., Andrienko, G., Fekete, J.-D., Görg, C., Kohlhammer, J., Melançon, G., [Visual analytics: Definition, process, and challenges], in: Information Visualization. Springer, pp. 154-175 (2008).

[5] Andrienko, G., Andrienko, N., Wrobel, S., "Visual analytics tools for analysis of movement data," ACM SIGKDD Explorations Newsletter 9, 38-46 (2007).

[6] Ramos, L., Silva, L., Santos, M.Y., Pires, J.M., "Detection of road accident accumulation zones with a visual analytics approach," Procedia Computer Science 64, 969-976 (2015).

[7] SteadieSeifi, M., Dellaert, N.P., Nuijten, W., Van Woensel, T. and Raoufi, R., "Multimodal freight transportation planning: A literature review," European journal of operational research, 233(1), pp.1-15 (2014).

[8] Lu, Y., Wang, H., Landis, S. and Maciejewski, R., "A visual analytics framework for identifying topic drivers in media events," IEEE transactions on visualization and computer graphics, 24(9), pp.2501-2515 (2017).

[9] Xiao, L., Gerth, J. and Hanrahan, P., "Enhancing Visual Analysis of Network Traffic Using a Knowledge Representation", 2006 IEEE Symposium on Visual Analytics Science and Technology. IEEE, pp. 107-114 (2006).

[10]DiBiase, D., MacEachren, A.M., Krygier, J.B., Reeves, C., "Animation and the role of map design in scientific visualization," Cartography and geographic information systems 19, 201-214 (1992). 